\title{
Faktor-faktor yang Berhubungan dengan Keikutsertaan Pria Mengikuti KB di Wilayah Kerja Puskesmas Blang Rakal Kecamatan Pintu Rime Gayo Tahun 2017
}

\author{
Factors Related to The Participation of Men in Following The KB in The Region \\ Working Puskesmas Blang Rakal Kecamatan Pintu Rime Gayo Tahun 2017

\section{Hervina Faralico ${ }^{* 1}$, Mido Ester Sitorus ${ }^{2}$} \\ ${ }^{1,2}$ Program Studi Kesehatan Masyarakat, Universitas Sari Mutiara Indonesia, Jln Kapten Muslim No. 77 Medan, \\ 20123, Indonesia \\ *Korespondensi Penulis: hervinsvinz@ymail.com
}

\begin{abstract}
Abstrak
Rendahnya tingkat partisipasi pria dalam menggunakan alat kontrasepsi dipengaruhi oleh banyak faktor seperti umur, sosial budaya, agama, ekonomi, serta pengetahuan pria terhadap kontrasepsi. Tujuan dari penelitian ini adalah untuk mengetahui faktor-faktor yang berhubungan dengan keikutsertaan pria mengikuti KB di wilayah kerja Puskesmas Blang Rakal Kecamatan Pintu Rime Gayo Tahun 2017. Jenis penelitian ini berupa observasional dengan metode pendekatan cross-sectional. Dalam penelitian ini yang menjadi populasi adalah seluruh pria atau pasangan usia subur di wilayah kerja Puskesmas Blang Rakal Kecamatan Pintu Rime Gayo yang berjumlah 87 orang dan sampel merupakan total populasi. Data dianalisis menggunakan uji chi-square. Hasil penelitian diperoleh : ada hubungan pengetahuan, sikap, budaya, sumber informasi, dukungan isteri dengan keikutsertaan pria mengikuti KB, faktor yang dominan berhubungan dengan keikutserta pria mengikuti KB di wilayah kerja Puskesmas Blang Rakal Kecamatan Pintu Rima Gayo adalah faktor sikap suami/ pria. Saran dalam penelitian ini adalah agar suami dapat memahami tentang ber-KB, maka para suami dapat mencari informasi melalui petugas kesehatan yang diantaranya cara mengatur jarak untuk memiliki anak. Dari informasi yang diperoleh tersebut dapat menambah pengetahuan sehingga dapat merubah sikap dengan ikut serta dalam ber-KB. Demikian pula Puskesmas dalam memberikan pelayanan kesehatan kepada masyarakat dapat melakukan sosialisasi ber-KB agar masyarakat bersedia menjadi akseptor KB khususnya para suami serta dapat mengajukan penambahan anggaran persediaan alat kontrasepsi kepada Dinas Kesehatan setempat.
\end{abstract}

Kata Kunci : keikutsertaan pria mengikuti KB, faktor yang berhubungan

\section{Abstract}

The low level of male participation in using contraception is influenced by many factors such as age, socio-cultural, religious, economic, and men's knowledge of contraception. The purpose of this study was to determine the factors associated with men's participation in family planning in the working area of Blang Rakal Health Center, Pintu Rime Gayo District of 2017. This type of research was observational with a cross-sectional approach. In this 
study the population is all men or couples of childbearing age in the working area of Blang Rakal Public Health Center, Pintu Rime Gayo District, which amounts to 87 people and the sample is the total population. Data were analyzed using the chi-square test. The results were obtained: there was a relationship between knowledge, attitudes, culture, sources of information, wife support with male participation in family planning, the dominant factors related to male participation in family planning in the working area of Blang Rakal Public Health Center, Pintu Rima Gayo District were husband / male attitudes. The suggestion in this study is that husbands can understand about family planning, so husbands can find information through health workers, including how to set the distance to have children. From the information obtained can increase knowledge so that it can change attitudes by participating in family planning. Likewise the Puskesmas in providing health services to the community can carry out family planning socialization so that people are willing to become family planning acceptors, especially husbands and can submit additional budget for contraceptive supplies to the local Health Service.

Keywords: Men's participation in family planning, related factors

\section{PENDAHULUAN}

Indonesia merupakan salah satu negara berkembang dengan berbagai jenis masalah. Masalah utama yang dihadapi Indonesia adalah dibidang kependudukan yang masih tingginya pertumbuhan penduduk. Semakin tinggi pertumbuhan penduduk semakin besar usaha yang dilakukan untuk mempertahankan kesejahteraan rakyat. Oleh karena itu pemerintah terus berupaya untuk menekan laju pertumbuhan dengan program keluarga berencana Badan Kependudukan dan Keluarga Berencana Nasional (BKKBN). Meskipun telah dilakukan kegiatan-kegiatan sosialisasi kepada masyarakat, namun jumlah peserta program MKET masih rendah (BKKBN, 2011).

Sementara itu menurut data Riskesdas (2013) diketahui bahwa persentase peserta KB baru dan KB aktif pada akseptor MOP dan kondom di Indonesia adalah untuk akseptor MOP dalam KB baru yaitu Aceh 33 jiwa (0,02\%), Sumatera Utara 4.722 jiwa (1,05\%) dan Jawa Barat 3.235 jiwa (0,21\%). Akseptor kondom dalam KB baru yaitu Sumatera Utara 60.898 jiwa (13,51\%), Gorontalo 2.245 jiwa (4,89\%) dan Maluku Utara 1.805 jiwa $(4,11 \%)$. Sedangkan KB aktif dalam akseptor MOP yaitu Jawa Barat 60.709 jiwa (0,86\%), Sumatera Utara 10.475 jiwa (0,72\%) dan Aceh 218 jiwa (0,04\%). Akseptor kondom dalam KB aktif yaitu Sumatera Utara 108.722 jiwa (7,48\%) dan Aceh 61.150 jiwa (9,10\%). Dalam hal ini jumlah PUS untuk Sumatera Utara 2.210.958 jiwa, Jawa Barat 9.047.576 jiwa, Jawa Timur 7.740.907 jiwa dan Papua Barat 146.097 jiwa.

Di Provinsi Aceh diketahui bahwa pencapaian peserta KB telah diupayakan untuk meningkatkan keikutsertaan pria dalam ber-KB, akan tetapi hasilnya masih jauh dari yang 
diharapkan dimana hanya 4.538 peserta atau 3,13\% dari total peserta KB yang terdiri dari 10 peserta KB MOP $(0,01 \%)$ dan 4.528 peserta KB kondom (3,12\%). Apabila dibandingkan dengan sasaran peserta KB pria tahun 2009 yang berjumlah 39.691 peserta, maka pencapaian peserta KB pria secara provinsi 2015 mencapai angka 11,44\%. Angka ini masih jauh dari sasaran enam bulanan sebesar 50\%. Jika dilihat dari per metoda, pencapaian MOP baru $43,48 \%$, sedangkan kondom hanya 11,41\% (BKKBN, 2016).

Berdasarkan data Kabupaten Bener Meriah diketahui bahwa target pencapaian KB pria ditetapkan sebesar 30\% yang mengacu kepada target provinsi Aceh dimana diperoleh pada tahun 2014, persentase peserta KB Baru dan KB Aktif pada akseptor MOP (9,10\%). Sedangkan KB Baru pada akseptor Kondom (9,62\%) dan KB Aktif pada akseptor Kondom (384,47\%). Dalam hal ini jumlah PUS di Bener Meriah yaitu 2058 jiwa (BKKBN, 2016).

Data dari Puskesmas Blang Rakal Kecamatan Pintu Rime Gayo Kabupaten Bener Meriah pada tahun 2017 diketahui mengalami peningkatan dari tahun-tahun sebelumnya dimana target Puskesmas untuk KB pria sebesar 30\%. Pada tahun 2016 jumlah Pasangan Usia Subur sebanyak 63 keluarga dengan persentase pria KB 17,5\%, pada tahun 2015 jumlah PUS sebanyak 72 keluarga dengan persentase 22,2\% dan pada tahun 2014, PUS sebanyak 65 keluarga dengan persentase pria KB 18,5\%.

Berkaitan dengan data di atas, survei awal yang dilakukan oleh peneliti di Puskesmas Blang Rakal diketahui bahwa masih rendahnya keikutsertaan pria dalam ber-KB. Dari hasil wawancara kepada petugas kesehatan diketahui bahwa pria yang memakai alat kontrasepsi kesemuannya memakai kondom karena diantara beberapa masih keinginan untuk mempunyai anak. Tujuan penelitian ini bertujuan untuk mengetahui faktor-faktor yang berhubungan dengan keikutsertaan pria mengikuti KB di Wilayah Kerja Puskesmas Blang Rakal Kecamatan Pintu Rime Gayo Tahun 2017.

\section{METODE PENELITIAN}

Jenis penelitian ini berupa observasional dengan metode pendekatan cross-sectional. Dalam penelitian ini yang menjadi populasi adalah seluruh pria atau pasangan usia subur di wilayah kerja Puskesmas Blang Rakal Kecamatan Pintu Rime Gayo yang berjumlah 87 orang. Data dianalisis menggunakan uji chi-square. 


\section{HASIL DAN PEMBAHASAN}

\section{Analisa Univariat}

Tabel 1. Distribusi Frekuensi Karakteristik Responden

\begin{tabular}{clcc}
\hline No & \multicolumn{1}{c}{ Karakteristik Responden } & n & \% \\
\hline 1. & Umur & & \\
& $\leq 25$ tahun & 21 & 24,1 \\
& 26-30 tahun & 47 & 54,1 \\
& $>30$ tahun & 19 & 21,8 \\
2. & Pendidikan & & \\
SMP & 8 & 9,2 \\
SMA & 76 & 87,4 \\
Perguruan Tinggi & 3 & 3,4 \\
3. Pekerjaan & & 5,8 \\
PNS & 5 & 1,2 \\
TNI / Polri & 1 & 13,8 \\
& Pegawai Swasta & 12 & 25,2 \\
Wiraswasta & 22 & 54,0 \\
Petani & 47 & $\mathbf{1 0 0}$ \\
\hline
\end{tabular}

Berdasarkan tabel di atas diketahui bahwa umur responden mayoritas 26 - 30 tahun sebanyak 54,1\%, pendidikan responden mayoritas SMA sebanyak $87,4 \%$ dan pekerjaan responden mayoritas petani sebanyak 54\%).

\section{Analisa Bivariat}

Tabel 2. Hubungan antara Pengetahuan dengan Keikutsertaan Pria Mengikuti KB di Wilayah Kerja Puskesmas Blang Rakal Kecamatan Pintu Rime Gayo Tahun 2017

\begin{tabular}{|c|c|c|c|c|c|}
\hline \multirow{3}{*}{ Pengetahuan } & \multicolumn{4}{|c|}{ Keikutsertaan KB } & \multirow{3}{*}{$\begin{array}{c}p \\
\text { value }\end{array}$} \\
\hline & \multicolumn{2}{|c|}{ Menggunakan } & \multicolumn{2}{|c|}{$\begin{array}{c}\text { Tidak } \\
\text { Menggunakan }\end{array}$} & \\
\hline & $\mathbf{n}$ & $\%$ & n & $\%$ & \\
\hline Baik & 7 & 6,7 & 5 & 4,8 & \multirow{3}{*}{0,000} \\
\hline Kurang Baik & 45 & 43,3 & 47 & 45,2 & \\
\hline Jumlah & 24 & 27,6 & 63 & 72,4 & \\
\hline
\end{tabular}

Hasil uji statistik diperoleh nilai $\mathrm{p}=0,000$ yang menunjukkan ada hubungan pengetahuan dengan keikutsertaan pria mengikuti $\mathrm{KB}$ di wilayah kerja Puskesmas Blang Rakal Kecamatan Pintu Rime Gayo Tahun 2017. Nilai OR = 7,771 yang menunjukkan bahwa pria berpengetahuan kurang baik akan 7,771 kali tidak menggunakan KB dibandingkan dengan pria yang berpengetahuan baik. 
Tabel 3. Hubungan antara Sikap dengan Keikutsertaan Pria Mengikuti KB di Wilayah Kerja Puskesmas Blang Rakal Kecamatan Pintu Rime Gayo Tahun 2017

\begin{tabular}{|c|c|c|c|c|c|}
\hline \multirow{3}{*}{ Sikap } & \multicolumn{4}{|c|}{ Keikutsertaan KB } & \multirow{3}{*}{$\begin{array}{c}p \\
\text { value }\end{array}$} \\
\hline & \multicolumn{2}{|c|}{ Menggunakan } & \multicolumn{2}{|c|}{$\begin{array}{c}\text { Tidak } \\
\text { Menggunakan }\end{array}$} & \\
\hline & $\mathbf{n}$ & $\%$ & $\mathbf{n}$ & $\%$ & \\
\hline Positif & 16 & 18,4 & 10 & 11,5 & \\
\hline Negatif & 8 & 9,2 & 53 & 60,9 & 0,000 \\
\hline Jumlah & 24 & 27,6 & 63 & 72,4 & \\
\hline
\end{tabular}

Hasil uji statistik diperoleh nilai $\mathrm{p}=0,000$ yang menunjukkan ada hubungan sikap dengan keikutsertaan pria mengikuti KB di wilayah kerja Puskesmas Blang Rakal Kecamatan Pintu Rime Gayo Tahun 2017. Nilai OR $=10,600$ yang menunjukkan bahwa pria dengan sikap negatif akan 10,600 kali tidak mengikuti KB dibandingkan dengan pria dengan sikap positif.

Tabel 4. Hubungan Antara Budaya Dengan Keikutsertaan Pria Mengikuti KB di Wilayah Kerja Puskesmas Blang Rakal Kecamatan Pintu Rime Gayo Tahun 2017

\begin{tabular}{cccccc}
\hline & \multicolumn{4}{c}{ Keikutsertaan KB } & \multirow{2}{*}{$\begin{array}{c}\text { Tidak } \\
\text { Budaya }\end{array}$} \\
\cline { 2 - 5 } & \multicolumn{2}{c}{ Menggunakan } & \multicolumn{2}{c}{$\begin{array}{c}\text { Menggunakan } \\
\text { value }\end{array}$} & \\
\cline { 2 - 5 } & $\mathbf{n}$ & $\mathbf{0}$ & $\mathbf{n}$ & $\boldsymbol{\%}$ & \\
\hline Tidak Mendukung & 11 & 12,6 & 12 & 13,8 & \\
Mendukung & 13 & 14,9 & 51 & 58,6 & 0,011 \\
\hline Jumlah & 24 & 27,6 & 63 & 72,4 & \\
\hline
\end{tabular}

Hasil uji statistik diperoleh nilai $\mathrm{p}=0,011$ yang menunjukkan ada hubungan budaya dengan keikutsertaan pria mengikuti KB di wilayah kerja Puskesmas Blang Rakal Kecamatan Pintu Rime Gayo Tahun 2017. Nilai OR = 3,596 yang menunjukkan bahwa pria dengan budaya rendah akan 3,596 kali tidak menggunakan KB dibandingkan dengan pria dengan budaya tinggi. 
Tabel 5. Hubungan Antara Sumber Informasi dengan Keikutsertaan Pria Mengikuti KB di Wilayah Kerja Puskesmas Blang Rakal Kecamatan Pintu Rime Gayo Tahun 2017

\begin{tabular}{|c|c|c|c|c|c|}
\hline \multirow{3}{*}{ Sumber Informasi } & \multicolumn{4}{|c|}{ Keikutsertaan KB } & \multirow{3}{*}{$\begin{array}{c}p \\
\text { value }\end{array}$} \\
\hline & \multicolumn{2}{|c|}{ Menggunakan } & \multicolumn{2}{|c|}{$\begin{array}{c}\text { Tidak } \\
\text { Menggunakan }\end{array}$} & \\
\hline & $\mathbf{n}$ & $\%$ & $\mathbf{n}$ & $\%$ & \\
\hline Baik & 13 & 14,9 & 9 & 10,3 & \\
\hline Kurang Baik & 11 & 12,6 & 54 & 62,1 & 0,000 \\
\hline Jumlah & 24 & 27,6 & 63 & 72,4 & \\
\hline
\end{tabular}

Hasil uji statistik diperoleh nilai $\mathrm{p}=0,000$ yang menunjukkan ada hubungan budaya dengan keikutsertaan pria mengikuti KB di wilayah kerja Puskesmas Blang Rakal Kecamatan Pintu Rime Gayo Tahun 2017. Nilai OR = 3,596 yang menunjukkan bahwa pria dengan informasi kurang baik akan 7,091 kali tidak menggunakan KB dibandingkan dengan pria dengan informasi yang baik.

Tabel 6. Hubungan antara Dukungan Isteri dengan Keikutsertaan Pria Mengikuti KB di Wilayah Kerja Puskesmas Blang Rakal Kecamatan Pintu Rime Gayo Tahun 2017

\begin{tabular}{|c|c|c|c|c|c|}
\hline \multirow{3}{*}{ Dukungan Isteri } & \multicolumn{4}{|c|}{ Keikutsertaan KB } & \multirow{3}{*}{$\begin{array}{c}p \\
\text { value }\end{array}$} \\
\hline & \multicolumn{2}{|c|}{ Menggunakan } & \multicolumn{2}{|c|}{$\begin{array}{c}\text { Tidak } \\
\text { Menggunakan }\end{array}$} & \\
\hline & $\mathbf{n}$ & $\%$ & $\mathbf{n}$ & $\%$ & \\
\hline Mendukung & 14 & 16,1 & 11 & 12,6 & \multirow{3}{*}{0,000} \\
\hline Tidak Mendukung & 10 & 11,5 & 52 & 59,8 & \\
\hline Jumlah & 24 & 27,6 & 63 & 72,4 & \\
\hline
\end{tabular}

Hasil uji statistik diperoleh nilai $\mathrm{p}=0,000$ yang menunjukkan ada hubungan budaya dengan keikutsertaan pria mengikuti KB di wilayah kerja Puskesmas Blang Rakal Kecamatan Pintu Rime Gayo Tahun 2017. Nilai OR =6,618 yang menunjukkan bahwa pria yang tidak didukung isteri akan 6,618 kali tidak menggunakan KB dibandingkan dengan pria yang didukung isteri.

Tabel 7. Hasil Analisa Multivariat

\begin{tabular}{llcccc}
\hline \multirow{2}{*}{ No } & \multirow{2}{*}{ Variabel } & \multicolumn{2}{c}{ Tahap 1 } & \multicolumn{2}{c}{ Tahap 2 } \\
\cline { 3 - 6 } & & $\boldsymbol{p}$-value & OR & $\boldsymbol{p}$-value & OR \\
\hline 1. & Pengetahuan & 0,001 & 26,378 & 0,001 & 25,397 \\
2. & Sikap & 0,000 & 35,390 & 0,000 & 33,137 \\
3. & Budaya & 0,190 & 3,213 & - & - \\
4. & Sumber Informasi & 0,012 & 10,461 & 0,007 & 11,151 \\
5. & Dukungan Isteri & 0,024 & 6,983 & 0,008 & 8,821 \\
\hline
\end{tabular}


Berdasarkan hasil analisa multivariat dapat diketahui bahwa ada 2 tahapan untuk mengetahui hasil analisis multivariat dimana pada tahap 1 diperoleh variabel budaya dengan nilai $\mathrm{p}>0,05$ sehingga tidak diikutsertakan pada tahap selanjutnya. Pada tahap akhir diketahui bahwa variabel pengetahuan dengan nilai $p=0,001(\mathrm{OR}=25,397)$, variabel sikap dengan nilai $\mathrm{p}=0,000(\mathrm{OR}=33,137)$, variabel sumber informasi dengan nilai $\mathrm{p}=0,007 \mathrm{OR}=$ 11,151) dan variabel dukungan isteri dengan nilai $\mathrm{p}=0,008(\mathrm{OR}=8,821)$ sehingga dapat disimpulkan bahwa faktor yang dominan berhubungan dengan keikutsertaan pria mengikuti KB adalah sikap.

\section{Hubungan Pengetahuan dengan Keikutsertaan Pria Mengikuti KB di Wilayah} Kerja Puskesmas Blang Rakal Kecamatan Pintu Rima Gayo Tahun 2017

Hasil penelitian menunjukkan pria berpengetahuan baik yang menggunakan $\mathrm{KB}$ 19,6\% dan yang tidak menggunakan KB 17,2\% serta pria berpengetahuan kurang baik yang ikut KB 8\% dan yang tidak menggunakan KB 55,2\%. Berdasarkan hasil uji chisquare diperoleh nilai $\mathrm{p}=0,000$ yang menunjukkan ada hubungan pengetahuan dengan keikutsertaan pria mengikuti KB di wilayah kerja Puskesmas Blang Rakal Kecamatan Pintu Rime Gayo Tahun 2017.

Hasil penelitian ini sesuai dengan pendapat Nomleni dkk (2014) yang menyatakan bahwa tingkat pengetahuan yang cukup tentang kontrasepsi merupakan dasar bagi pasangan suami isteri dalam memilih metode kontrasepsi. Kontrasepsi merupakan usahausaha untuk mencegah terjadinya kehamilan. Usaha-usaha itu dapat bersifat sementara dan permanen (Wiknjosastro, 2010). Pendapat tersebut sejalan dengan Pinem (2012) yang menyatakan bahwa pada hakekatnya KB bertujuan untuk mewujudkan keluarga dengan anak ideal, sehat, berpendidikan, sejahtera, berketahanan dan terpenuhi hak-hak reproduksinya (Pinem, 2012).

Dari uraian di atas dapat disimpulkan bahwa pengetahuan memberikan dampak positif terhadap pria untuk mengikuti KB. Pengetahuan tersebut dapat diperoleh pendidikan yang pernah dijalani atau melalui berbagai informasi lainnya.

\section{Hubungan Sikap Dengan Keikutsertaan Pria Mengikuti KB di Wilayah Kerja Puskesmas Blang Rakal Kecamatan Pintu Rima GayoTahun 2017}

Hasil penelitian menunjukkan bahwa $29,9 \%$ pria dengan sikap positif, terdapat $18,4 \%$ menggunakan KB dan 11,5\% tidak menggunakan KB. Dari 70,1\% pria dengan 
sikap negatif, terdapat 9,2\% yang menggunakan $\mathrm{KB}$ dan 60,9\% yang tidak menggunakan KB. Kemudian dari hasil uji statistik diperoleh nilai $\mathrm{p}=0,000$ yang menunjukkan ada hubungan sikap dengan keikutsertaan pria mengikuti KB di wilayah kerja Puskesmas Blang Rakal Kecamatan Pintu Rime Gayo Tahun 2017.

Hasil penelitian ini dapat ditinjau dari pendapat Walgito (2003) dalam Nasrulloh (2015) yang menyatakan bahwa sikap sangat berkaitan erat dengan tingkat pengetahuan seseorang, sikap seseorang terhadapsuatu objek menunjukkan pengetahuan orang tersebut terhadap objek yang bersangkutan. Dengan demikian seseorang yang memiliki pengetahuan baik tentang program KB, akan memiliki sikap positif juga terhadap program KB. Notoatmodjo (2012) menyatakan bahwa sikap merupakan reaksi atau respon yang masih tertutup dari seseorang terhadap suatu stimulus atau objek. Sikap juga merupakan kesiapan atau kesediaan untuk bertindak dan juga merupakan pelaksanaan motif tertentu.

Dari uraian di atas dapat disimpulkan bahwa sikap pria/ suami terhadap keikutsertaan mengikuti KB merupakan perilaku ke arah reaksi yang dapat dilakukan ataupun tidak dilakukan atau sikap merupakan kesiapan seseorang terhadap tindakan yang akan dilakukan.

\section{Hubungan Budaya dengan Keikutsertaan Pria Mengikuti KB di Wilayah Kerja Puskesmas Blang Rakal Kecamatan Pintu Rima GayoTahun 2017}

Hasil penelitian menunjukkan bahwa dari $26,4 \%$ pria yang tidak sesuai budaya, 12,6\% yang menggunakan KB dan 13,8\% tidak menggunakan KB. Dari 73,6\% pria sesuai budaya, terdapat $14,9 \%$ yang menggunakan $\mathrm{KB}$ dan $58,6 \%$ tidak menggunakan KB. Kemudian dari uji statistik diperoleh nilai $\mathrm{p}=0,011$ yang menunjukkan ada hubungan budaya dengan keikutsertaan pria mengikuti KB di wilayah kerja Puskesmas Blang Rakal Kecamatan Pintu Rime Gayo Tahun 2017.

Hasil penelitian ini sesuai dengan pendapat Aritonang (2012) yang menyatakan bahwa sebagai mahluk sosial, manusia hidup tidak terlepas dari budaya bahkan dapat dipengaruhi oleh budaya dimana ia hidup. Budaya menyangkut adat istiadat, tradisi, kebiasaan aturan-aturan dan pendapat-pendapat. Penggunaan alat kontrasepsi juga turut dipengaruhi oleh faktor budaya mengingat penggunanya hidup dalam lingkungan budaya. 


\section{Hubungan Sumber Informasi dengan Keikutsertaan Pria Mengikuti KB di Wilayah} Kerja Puskesmas Blang Rakal Kecamatan Pintu Rima Gayo Tahun 2017

Hasil penelitian menunjukkan bahwa dari $25,3 \%$ pria dengan informasi baik, terdapat $14,9 \%$ yang menggunakan KB dan 10,3\% tidak menggunakan KB. Dari 74,7\% pria dengan informasi kurang baik, terdapat $12,6 \%$ yang menggunakan $\mathrm{KB}$ dan $62,1 \%$ tidak menggunakan KB. Kemudian hasil uji statistik diperoleh nilai $\mathrm{p}=0,000$ yang menunjukkan ada hubungan budaya dengan keikutsertaan pria mengikuti KB di wilayah kerja Puskesmas Blang Rakal Kecamatan Pintu Rime Gayo Tahun 2017.

Hasil penelitian ini dapat ditinjau dari pendapat Jajang (2005) yang menyatakan bahwa informasi adalah suatu keterangan, penerangan, atau data yang telahdi proses ke dalam suatu bentuk yang mempunyai arti bagi si penerima danmempunyai nilai yang nyata, sehingga dapat dipakai sebagai dasar untukmengambil keputusan untuk masa yang akan datang dan oleh Mubarak dan Chayatin (2009) dikemukakan bahwa kemudahan untuk memperoleh informasi dapat membantu mempercepatseseorang untuk memperoleh pengetahuan yang baru.

\section{Hubungan Dukungan Isteri dengan Keikutsertaan Pria Mengikuti KB di Wilayah}

\section{Kerja Puskesmas Blang Rakal Kecamatan Pintu Rima Gayo Tahun 2017}

Hasil penelitian menunjukkan bahwa dari $28,7 \%$ pria yang didukung isteri, terdapat 16,1\% yang menggunakan KB dan yang tidak menggunakan KB 12,6\%. Dari 71,3\% pria yang tidak didukung isteri, terdapat $11,5 \%$ yang menggunakan $\mathrm{KB}$ dan tidak menggunakan KB 59,8\%. Hasi uji statistik diperoleh nilai $\mathrm{p}=0,000$ yang menunjukkan ada hubungan budaya dengan keikutsertaan pria mengikuti KB di wilayah kerja Puskesmas Blang Rakal Kecamatan Pintu Rime Gayo Tahun 2017.

Hasil penelitian ini sesuai dengan pendapat BKKBN (2002) yang menyatakan bahwa kesadaran isteri akan hak-hak reproduksinya dan posisi setara dengansuami dalam pengambilan keputusan mengenai KB. Isteri harusmemahami bahwa perencanaan keluarga tidak ditentukan oleh suami saja, tetapi perlu dibahas bersama isteri.

\section{KESIMPULAN}

1. Ada hubungan pengetahuan dengan keikutsertaan pria mengikuti $\mathrm{KB}$ di wilayah kerja Puskesmas Blang Rakal Kecamatan Pintu Rima Gayo. 
2. Ada hubungan sikap dengan keikutsertaan pria mengikuti KB di wilayah kerja Puskesmas Blang Rakal Kecamatan Pintu Rima Gayo.

3. Ada hubungan budaya dengan keikutsertaan pria mengikuti $\mathrm{KB}$ di wilayah kerja Puskesmas Blang Rakal Kecamatan Pintu Rima Gayo.

4. Ada hubungan sumber informasi dengan keikutsertaan pria mengikuti KB di wilayah kerja Puskesmas Blang Rakal Kecamatan Pintu Rima Gayo.

5. Ada hubungan dukungan isteri dengan keikutsertaan pria mengikuti KB di wilayah kerja Puskesmas Blang Rakal Kecamatan Pintu Rima Gayo.

\section{SARAN}

Berdasarkan hasil penelitian yang telah diperoleh, maka saran yang disampaikan adalah sebagai berikut:

1. Pria / Suami

Agar suami dapat memahami tentang ber-KB, maka para suami dapat mencari informasi melalui petugas kesehatan yang diantaranya cara mengatur jarak untuk memiliki anak. Dari informasi yang diperoleh tersebut dapat menambah pengetahuan sehingga dapat merubah sikap dengan ikut serta dalam ber-KB.

2. Puskesmas

Puskesmas dalam memberikan pelayanan kesehatan kepada masyarakat dapat melakukan sosialisasi ber-KB agar masyarakat bersedia menjadi akseptor KB khususnya para suami serta dapat mengajukan penambahan anggaran persediaan alat kontrasepsi kepada Dinas Kesehatan setempat.

\section{DAFTAR PUSTAKA}

Ayunda Sri Samira. (2015). Faktor-faktor yang berhubungan dengan pemilihan metode kontrasepsi oleh PUS di desa peunyerat kecamatan banda raya banda aceh.

Budisantoso Iman Saptoni. (2015) . Faktor-Faktor Yang Berhubungan Dengan Partisipasi Pria Dalam Keluarga Berencana Di Kecamatan Jetis Kabupaten Bantu.

BKKBN. (2012). Survei Demografi dan Kesehatan Indonesia Pusat Statistik, Badan Kependudukan Berencana Nasional dan Kementerian Kesehatan. Jakarta.

, (2002). Ada Apa dengan Gender dalam KB dan Kesetaraan Reproduksi,Jakarta. http://www.gemapria.com

Dewi, Sunarsih, 2011. Asuhan Kebidanan pada Ibu Nifas. Yogyakarta : Salemba Medika. 
Hartanto Hanafi. (2011). Keluarga Berencana dan Kontrasepsi. Jakarta : Pustaka Sinar Harapan.

Indira Laksmi, (2011) .Faktor-faktoryang mempengaruhi pemilihan jenis kontrasepsi yang digunakan pada keluarga. Semarang: UNDIP 2011.

Nasution Masro, GAN Dien, Ramadani Meri. (2012). Faktor-faktor yang mempengaruhi perilaku akseptor KB pria di wilayah kerja puskesmas ambacang kotapadang.

Nisa Dorazatun, Hasan Nawar. 2015. Faktor yang berhubungan dengan keikutsertaan pria dalam keluarga berencana di kelurahan cilenggang serpong tanggerang selatan.

Nomleni, Emawati (2014). Faktor-faktor yang berhubungan denganpemilihan alat kontrasepsi pada PUS di RSKD Makasar.

Nugroho T,Utama I.B, 2014. Masalah Kesehatan Reproduksi Wanita. Yogyakarta : Nuha Medika.

Nasrulloh, Ahmad, (2015). Hubungan Antara Pengetahuan, Sikap dan Dukungan Keluarga dengan Keikutsertaan Pasangan Usia Subur (PUS) dalam Ber-KB di Wilayah Kerja Puskesmas Purwosari Kota Surakarta. Surakarta : Jurnal Universitas Muhammdiyah Surakarta.

Nasution, Masro; Dien GAN, Meri Ramadani, (2012) .Faktor-Faktor Yang Mempengaruhi Perilaku Akseptor Kb Pria Di Wilayah Kerja Puskesmas Ambacang Kota Padang Tahun 2012. Jurnal : Universitas Udayana.

Pinem S. (2009). Kesehatan Reproduksi dan Kontrasepsi. Jakarta: Trans Info Media.

Riskesdes. (2013). Data dan Informasi KB Di Aceh. Tahun 2013.

Sulistyawati. (2013). Pelayanan Keluarga Berencana. Jakarta: Penerbit Salemba Medika.

Sugiyono. (2010). Metode Penelitian Kuntitatif Kualitatif dan R \& D,Bandung : Alfabeta.

Yuhedi, Kurniawati. (2013). Buku Ajar Kependudukan dan Pelayanan KB. Jakarta : EGC 